\title{
$\mathrm{PH} 91$
}

\section{Wikimedia España y la difusión del patrimonio cultural}

Wikimedia España es una asociación sin ánimo de lucro que trabaja en pro del conocimiento libre, principalmente a través de Wikipedia y sus proyectos hermanos, en todas las lenguas de España. Nacida en 2011, sus actividades se basan en el trabajo voluntario y desinteresado de centenares de personas cuyo objetivo es el del libre acceso al conocimiento. En ese marco, una de sus principales áreas de trabajo es la organización de actividades y proyectos que buscan la creación y difusión de contenidos, desde acciones de edición en Wikipedia sobre un determinado tema hasta excursiones o coberturas de eventos para la obtención de fotografías.

Rubén Ojeda de la Roza | Wikimedia España

Iván Hernández Cazorla | Wikimedia España

URL de la contribución <www.iaph.es/revistaph/index.php/revistaph/article/view/3882>

Entre todas las actividades planteadas por Wikimedia España destacan especialmente, por el volumen de contenidos, los concursos y proyectos de fotografía. El objetivo es obtener imágenes con licencia libre para ilustrar contenidos en Wikipedia y el resto de proyectos Wikimedia, siempre difundiendo nuestro patrimonio a través de Internet. Esto es especialmente relevante si consideramos que la enciclopedia libre está entre los diez sitios web más visitados del mundo. A ello habría que añadir el valor de contar con tales recursos para múltiples usos, desde el ámbito educativo y divulgativo hasta el turístico.

La primera vez que se organizó un proyecto de este tipo en España fue en 2011; desde entonces ha crecido el número y variedad temática: monumentos (Wiki Loves Monuments, desde 2011); espacios naturales (Wiki Loves Earth, desde 2015); fiestas de interés turístico (Wiki Loves Folk, desde 2016); lugares de la Guerra Civil Española (en 2016); y municipios (desde 2015). Cada una de estas iniciativas conlleva la creación de listados de aquellos elementos que pueden ser fotografiados, siempre a partir de fuentes oficiales: la base de datos de bienes inmuebles del Ministerio de Educación, Cultura y Deporte; la Red Natura 2000 de la Unión Europea; o los catálogos autonómicos de fiestas de interés turístico.

Este proceso pone a disposición de toda la sociedad información básica sobre estos elementos (nombre, ubicación, coordenadas), y un acceso directo a Wikimedia

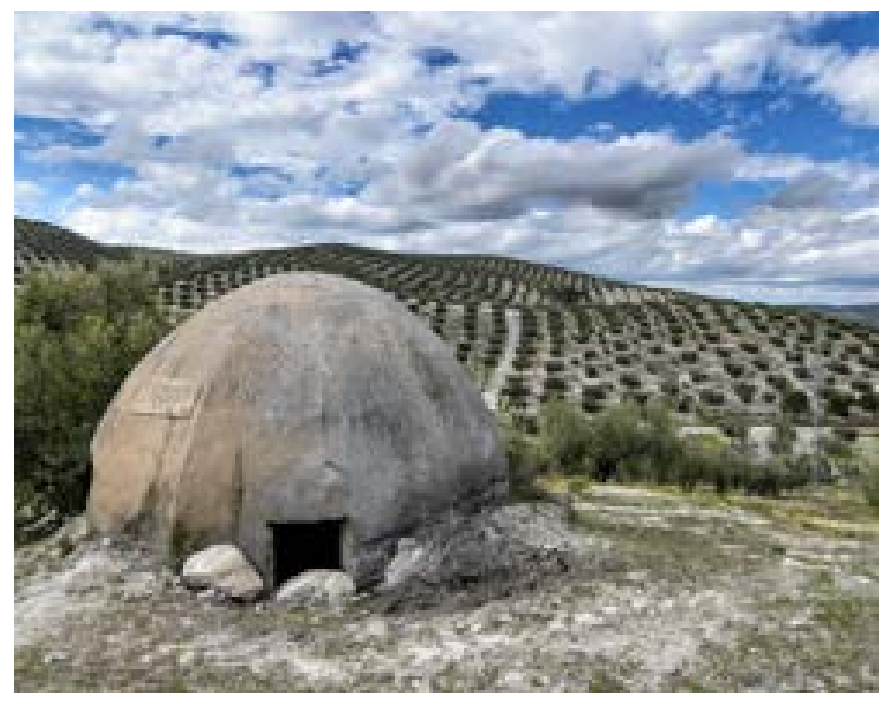

Búnker de Albendín (Córdoba) | foto Edmundo Sáez, CC BY-SA, Wikimedia Commons

Commons, donde se encuentran imágenes de ellos, con licencia libre, y se puede contribuir con más fotografías.

Wiki Loves Monuments es, sin duda, el más exitoso de todos los concursos. Su primera edición tuvo lugar en septiembre de 2010 en Países Bajos, y obtuvo más de 12.000 fotografías. A finales de ese año Wikimedia Nederland propuso a otros grupos Wikimedia la organización del concurso a nivel internacional. La segunda edición se celebró en 18 países, entre ellos España, y la última fue en 2016. En total se han obtenido más de 1.400 .000 fotografías, siendo reconocido en el libro 
Guinness de los récords como el mayor concurso fotográfico del mundo.

En el caso de España la cifra de imágenes obtenidas después de seis ediciones supera las 123.000. El foco de interés es, desde el principio, el conjunto de bienes de interés cultural, alcanzando en torno a 15.000 elementos. Sin embargo, desde 2015 el concurso se ha centrado únicamente en aquellos elementos que carecían de imagen alguna en Wikimedia Commons, principalmente monumentos ubicados en el medio rural, que reciben muchas menos visitas o son menos accesibles que los enclavados en ciudades.

Además de monumentos sin foto, también desde 2015 hemos añadido al concurso los listados de municipios españoles sin foto, con el ánimo de conseguir imágenes bajo licencia libre de todos aquellos núcleos de población que no cuentan con ninguna imagen libre en Commons. Es, sin duda, otra forma de visibilizar el rico patrimonio rural de nuestros pueblos.

La participación en todos estos proyectos ha sido, hasta el momento, elevada. Solo en la edición española de Wiki Loves Monuments han contribuido más de 2.800 personas. El uso real de todo este material es difícil de cuantificar pero, al menos en el ámbito Wikipedia, contamos con algunas estadísticas de uso en los propios artículos enciclopédicos. Así, en el mismo Wiki Loves Monuments, el total de imágenes distintas usadas desde la primera edición, en 2011, asciende a 20.219 mientras que el número de usos en las distintas versiones idiomáticas de Wikipedia es de 46.113.

El éxito nos anima a continuar con cada iniciativa y plantear otras nuevas. La difusión que se obtiene con todas ellas está fuera de toda duda, no solo a través del número de visitas en los proyectos Wikimedia, sino también gracias al banco de imágenes que se obtiene. Esto es especialmente relevante en los casos de patrimonio abandonado o dañado, cuyas fotografías se convierten en memoria para el futuro. Estas imágenes, recopiladas, categorizadas y puestas en uso ayudan a construir la historia del patrimonio material, inmaterial y natural que nos rodea.

\section{BIBLIOGRAFÍA}

- COMmONS: Wiki Loves Monuments 2010. En Wikimedia Commons, the free media repository <https://commons. wikimedia.org/w/index.php?title=Commons:Wiki Loves Monuments_2010\&oldid=135430634> [Consulta: 22/01/2017]

- ESTADísticAS internacionales. En Wikimedia España <https://www.wikilov.es/es/Wiki Loves Monuments/Estad\% C3\%ADsticas> [Consulta: 22/01/2017]

- GLAMorous. En Wikimedia Tool Labs <http://bit.ly/2jG9 LCV> [Consulta: 22/01/2017]

- LARGEST photography competition. En Guinness World Records <http://www.guinnessworldrecords.com/ world-records/largest-photography-competition/> [Consulta: 22/01/2017]

- Wikiproyecto: PATRIMONIO histórico. En Wikipedia Enciclopedia Libre <https://es.wikipedia.org/w/index.php?title= Wikiproyecto:Patrimonio_hist\%C3\%B3rico\&oldid=93213121> [Consulta: 22/01/2017]

- RODRÍGUEZ POSADA, E. J.; GONZÁLEZ BERDASCO, Á.; SIERRA CANDUELA, J. A.; NAVARRO SANZ, S.; SAORÍN, T. (2012) Wiki Loves Monuments 2011: experiencia en España y reflexiones desde la difusión del patrimonio cultural. En AIBAR, E.; FUSTER, M. (coord.) Dosier Investigación académica sobre la Wikipedia. Digithum, n. ${ }^{\circ}$ 14, pp. 106-117 <http://digithum. uoc.edu/articles/abstract/10.7238/d.v0i14.1472/> [Consulta: 22/01/2017]

- The TOP 500 sites on the web. En Alexa <http://www.alexa. com/topsites> [Consulta: 22/01/2017]

- WIKI Loves Monuments Statistics. Septiembre de 2016 . En Wiki Loves Monuments <https://tools.wmflabs.org/wlm-stats/> [Consulta: 22/01/2017]

- WIKIMEDIA España. En Wikimedia Meta-Wiki <https:// meta.wikimedia.org/w/index. php?title=Wikimedia Espa\%C3\%B1a\&oldid=16021917> [Consulta: 22/01/2017]

- WIKIPROYECTO: Ningún municipio español sin fotografía. En Wikipedia Enciclopedia Libre <https://es.wikipedia.org/w/ index.php?title=Wikiproyecto:Ning\%C3\%BAn_municipio espa\%C3\%B1ol_sin_fotograf\%C3\%ADa\&oldid=95934612> [Consulta: 22/01/2017] 